\title{
COMMUNITY PARTICIPATION IN PREVENTION OF COMMUNICABLE DISEASES IN RURAL AREAS OF PAKISTAN: A REVIEW OF LITERATURE
}

\author{
Farzana Iqbal ${ }^{\square}$, Muhammad Hussain', Hafiz Sabghatullah ${ }^{2}$
}

\begin{abstract}
BACKGROUND: There is huge burden of both communicable and noncommunicable diseases in healthcare systems. Community engagement is the diverse beneficial relationship between community stakeholders, primary healthcare system and professionals over a wide variety of tasks, their role and participation in decision making for enhancing community health.
\end{abstract}

OBJECTIVES: This paper focuses to present the use of Ladder of Community Participation as a framework to integrate community health problems in Pakistan. Additional focus is on local issues and the integration of the model according to socio-politico-economic structure of Pakistan

METHODS: Research articles were reviewed from PubMed, Medline, EBSCO, and CINAHL. Different key words such as "community engagement", "community participation", "communicable diseases", "Ladder framework", were used along with focus on the most recent and human based studies. After thorough review of the abstracts, selected researches were used to integrate the concept of community engagement in prevention of communicable diseases.

REVIEW: Review of the literature showed that local healthcare services alone cannot make sufficient efforts to uplift the health status of the communities. Community based collaborative interventions are often cost effective, sustainable and effective in managing outbreaks and other communicable diseases. It is imperative to engage the local communities and its stakeholders for an informative, collaborative and success oriented approach. Moreover, educating the community stakeholders for on-going basis can be an asset to the public health initiatives in the community. The ladder of community participation presented in this paper guides the public health workers and community stakeholders for step-wise integration of community and its resources in different programs about communicable disease prevention.

CONCLUSION: This ladder presents a continuum of different approaches, which will help in planning program management, feasibility assessment, evaluating ongoing interventions along with modification, and expanding community engagement approaches.

KEY WORDS: Community Participation (MeSH); Communicable Diseases (MeSH); Health system integration (Non-MeSH); Primary Health Care (MeSH); Health (MeSH); Community Health (MeSH); Public Health (MeSH); Pakistan (MeSH).

THIS ARTICLE MAY BE CITED AS: Iqbal F, Hussain M, Sabghatullah H. Community participation in prevention of communicable diseases in rural areas of Pakistan: a review of literature. Khyber Med Univ J 2020;13(2):। I8-22. https://doi.org/10.35845/kmuj.2021.20193

\section{INTRODUCTION}

$\mathrm{W}$ ith growing population, advancement of technology and complexity in the healthcare systems, the pattern of burden of diseases changes with time. In $21^{\text {st }}$ century, the challenges to the healthcare systems are increasing with the increasing number of communicable diseases (CDs) along with NonCommunicable Diseases (NCDs). This
I: Lahore School of Nursing, The University of Lahore, Lahore, Pakistan.

2: Royal College of Nursing, Swat, Pakistan.

Contact \# : +92-333-3083636

Email凶: farzana.iqbal@live.com

Date Submitted: March 26, 2020

Date Revised: June 21,202I

Date Accepted: June 26, 202I

includes the increasing prevalence of obesity, cardiovascular diseases and metabolic disorders such as thyroid and diabetes. These challenges are more diverse in low and middle income countries (LMICs) where the socioeconomic challenges negatively effecting the quality of life of the population.' Additionally, the risks of morbidities and mortalities regarding NCDs are different compared to the communicable diseases. ${ }^{2}$ It is because the fast rate of spread, higher influence of getting communicable diseases due to external factors such as environment, human to human and animal contact, and change in the genetic sequencing of pathogens more rapidly. ${ }^{3}$ Hence over the history, communicable diseases are more associated with mortalities and lifelong morbidities in their epidemics and endemics. ${ }^{4}$

To overcome the present and future challenges, it become inevitable for the healthcare system to focus more on the prevention of communicable diseases and bring masses into action through collaborative participation. This is only possible when the local communities are the part of community based interventions to combat it. ${ }^{5}$ One of the effective method of community participation in primary health is to inform, educate, collaborate and empower the community in the public health function. ${ }^{6}$ This is the responsibility of local health department and professionals such as physicians, nurses and social workers to involve them in the local community based interventions. A community oriented framework for engaging the community stakeholders help in effective planning, intelligent 
allocation of resources, and purposeful interventions for reducing the burden of communicable diseases ${ }^{7}$. Therefore, this paper will be discussing the integration of a model which will guide and enlighten the importance of community engagement in preventing and treating communicable diseases. This paper will focus on a local issue and will integrate the model according to socio-politicoeconomic structure of Pakistan.

\section{METHODS}

To assess and get insight into the importance of community participation in the prevention of communicable diseases in Pakistan, we reviewed different research papers. These researches were reviewed from PubMed, Medline, EBSCO, and CINAHL. Different key words such as "community engagement", "community participation", "communicable diseases", "Ladder framework", were used along with focus on the most recent and human based studies. After thorough review of the abstracts, selected researches were used to integrate the concept of community engagement in prevention of communicable diseases.

\section{REVIEW AND DISCUSSION}

History of Community Participation in Public Health Issues

Over the long period of history, community engagement always proven to be effective in the control of public health challenges which include both communicable and non-communicable diseases ${ }^{3}$. Community mobilization for sorting out their local challenges showed a wide range of effectiveness and sustainability in different interventional studies. For example, when chronic plagues emerged in $19^{\text {th }}$ and $20^{\text {th }}$ century, the public health stakeholders realized that they are unable to control and prevent the spread of deadly pandemics and epidemics without community participation. ${ }^{8}$ They mobilized the communities by engaging their stakeholders to develop awareness and enhance their practices related to immunization, hygiene practices and sanitization of different material and objects which were the main causes of these communicable diseases.' However, the burden of combating communicable diseases in $21^{\text {st }}$ century became more challenging because of the emergence of conspiracy theories, concepts of bioterrorism, and the availability of misleading information over the internet. ${ }^{10}$ Yet despite of all these factors, according to a study by Packard, one of the vital reason of failure in most global health interventions is the failure in engaging community as a partner. ${ }^{7}$

Community Participation and its Importance in the Prevention and Treatment of Communicable Diseases

Community engagement or involvement is the diverse beneficial relationship between the community stakeholders and primary healthcare system and professionals over a wide variety of tasks, their role in decision making and participation in decision making for enhancing the community health. ${ }^{6}$ It is misunderstood by the community as one sided relationship, whereas, in scientific language it is bilateral relation which involves interaction, listening to each other and setting mutually beneficial goals. ${ }^{7}$ In this kind of relationship the local healthcare system shares its health related or problem oriented expertise, budget and other available resources while the community offers it manpower, local wisdom, and community based strategies to ensure the effectiveness in the program." Community is a group of individual which shares common characteristics such as language, culture, ethnic background and have common challenges including health related problems. ${ }^{12}$ While public engagement is broad, community engagement is specific in terms of its interaction with a specific community, by specific group of specialists and for specific problems such as Hepatitis, Cholera, bacterial diseases such as Pneumonia, Tuberculosis, viruses such as Ebola, Congo Hemorrhagic Fever, and now the newly emerged pandemic of Noval Corona Virus 2019 or COVID- 19 etc. $^{7}$

\section{A Framework: Ladder of Community Participation}

The recent discovery related to the outbreak of Hepatitis B and C among the teenage and children in Sindh catch the attraction of media and government on a large extent. ${ }^{13}$ The reason of this widespread prevalence of Hepatitis B and $C$ become alarming to public health professionals and health system of the country. ${ }^{14}$ A team of World Health Organization (WHO) has been invited to investigate the root cause and possible solution for it. ${ }^{13}$ At an early stage, there were many conspiracy theories about the causes of this endemic but later it was identified that there were many reasons for it. The government moved its machinery to combat through diagnosing, treating and preventing the spread of Hepatitis B and C. ${ }^{14}$ However, there were some challenges identified in accelerating the community for support and voluntary participation.

There are different community health integration frameworks which the experts use to engage the community in the public health problems. ${ }^{15}$ In this review focused on the use of Ladder of Community Participation (Figure I) as a framework to integrate the community health problems in Pakistan. This ladder presents a continuum of different approaches which will help in the program management in planning, feasibility assessment, evaluating the ongoing interventions along with modification and expanding the community engagement approaches. ${ }^{6}$ It is also helpful in clarification of the roles and delegate the responsibilities. For this, the authors think this Ladder of Community Participation may help in better way. We will be discussing the steps of this ladder in details by integrating the current outbreak of Hepatitis B and $C$ and strategies used for countering it. There are few steps which are explained as follow;

\section{Initiating and Directing of Commu- nity Based Actions}

The first step of this ladder is initiating and directing the actions. For combating the outbreak of Hepatitis B and C, it is the responsibility of the healthcare system of the local district to accelerate the community for participating in medical camp and go through their diagnostic testing. The community stakeholders such as religious scholars, school teachers, and landlords should be taken in confidence and aware about the consequences of each outbreak. ${ }^{13}$ Moreover, accessibility and availability of the diagnostic facilities should be 


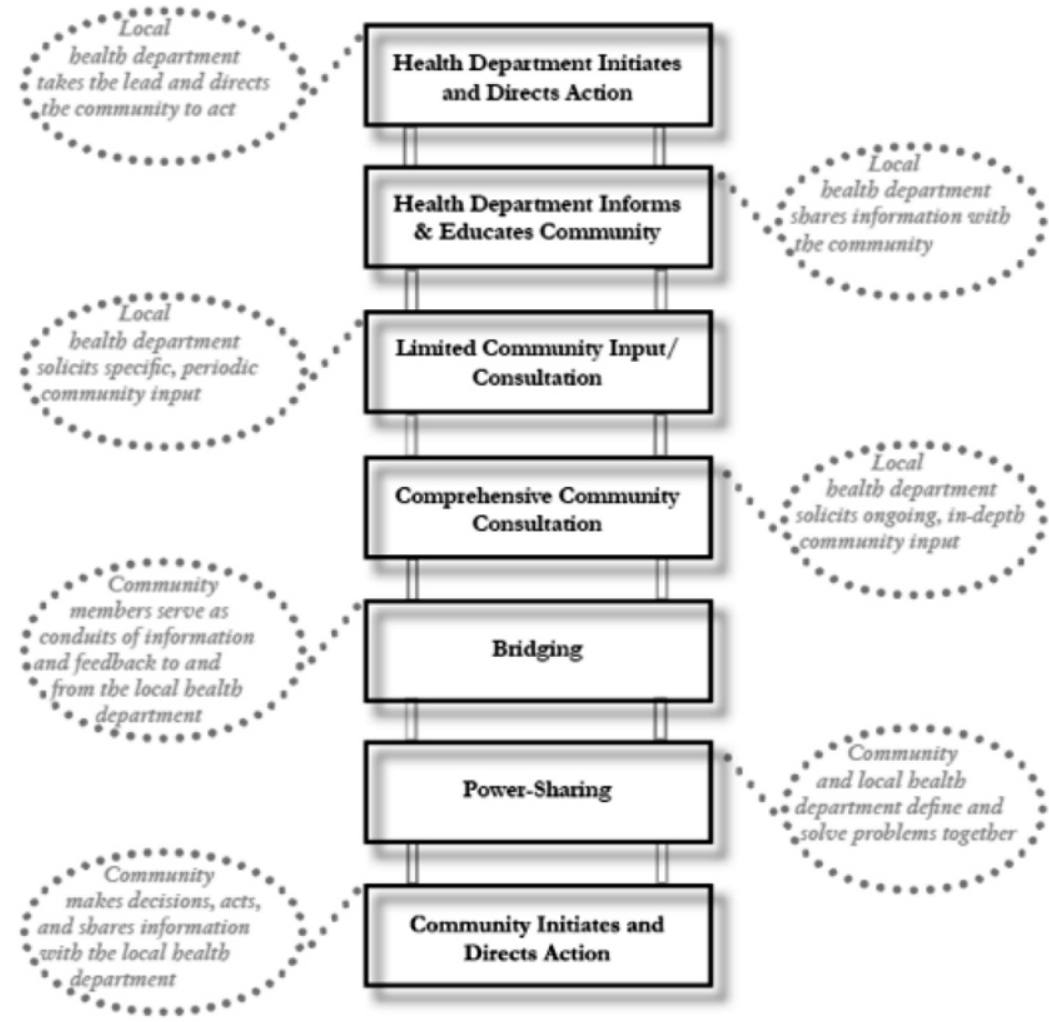

Figure I: The Ladder of Community Participation ${ }^{6}$

made possible by the healthcare institution. ${ }^{14}$ This is important because different studies revealed that involving community as a partner is a challenging task, and therefore should be taken as initial step in programming and designing the study or interventions.

\section{Informing and Educating the Community}

Giving information and education to the community is vital in preventing and combating the Hepatitis B and C in Larkana. There are different ways of educating and spreading the information such as pamphlets, flayers and other printed material while electronic media, especially the use of social media can be one of the very few important forces which can accelerate the masses. ${ }^{16}$ Providing information through one to one interaction is time consuming and need hard efforts. Therefore, if the healthcare system provide basic education related to the prevention of reusing of syringes, blood products, and razors etc. will help in reducing the spread of the disease. Additionally, those who want to get themselves checked for the disease, they can easily approach the assigned centers accordingly.

\section{Community Input and Consultation}

Community input and consultation gives a very useful insight to the solutions which is according to the needs and feasibility of the community. ${ }^{3,7}$ In Sindh, the local health department needs to integrate the community to meet their needs and provide culturally sensitive care to the patients and citizen for easily meeting their goals in their own language. It is also imperative for their information and education to produce the educational material in the local language. ${ }^{7}$ and to hire the community awareness volunteers who knows the social dynamics of the community. ${ }^{15}$

\section{Comprehensive Community Consultation}

In this step of the ladder of community engagement, the health system takes the input from the community on the ongoing interventions for the control of diseases. For example if the local health department faces challenges in creating the awareness and diagnosing the local citizen because of the associated stigma to Hepatitis B and C, it is important to engage the community stakeholders and discuss these issues comprehensively. ${ }^{17}$ Additionally, the health department may change its ongoing interventional strategies for a faster and sustainable health outcomes keeping in view the social dynamics of LMICs.

\section{Bridging}

Local health department mostly use this strategy to gain movement, engage the community and make a bridge of communication and interaction in between the community and the healthcare system by recruiting and volunteering the people from within the community. 1,7 Therefore, for the local healthcare system in Sindh, it is important that they should engage the local community educators and social workers so that they can serve as a bridge and entry point to the healthcare services. This is also the need of time to accelerate the local public for their community based activities in combating communicable diseases especially Hepatitis B and C. ${ }^{7}$

\section{Power-Sharing}

This step of the ladder reflects that none of the interventions will result in optimal level until there is equal stake of healthcare system and community. This principle means sharing of the power of decision making to the local community so that they can decide best for themselves among the available options. ${ }^{6,18}$ Power sharing makes it easy as all the outcomes depend on the commitment of time and resources. ${ }^{19}$ If the local healthcare system shares the power of decision with the community, the community stakeholders may decide best for deploying the resources in the most affected areas of Hepatitis B and $C$ in Sindh. It is because they know their social dynamics and they will better understand the situation being in the community. 2,19

\section{Community Initiates and Directs Action}

According to this step of community engagement, the community is independent of the health system in its decision making and there is no or very 
little influence of the healthcare system on the community. ${ }^{6}$ This kind of initiative gives better option to the community to collaborate actively with the healthcare department and also to direct its focus and intervention for the future goals. ${ }^{18}$ For example, if the local community initiate and direct its action against the control and prevention of Hepatitis B and $C$ in Sindh, they will be able to look and take care of the emerging issues in future in such communities. Also, in this step, the community shares its information in more accurate manner with the health department which is out of the box and influence of any external factor. ${ }^{12}$

\section{CONCLUSION AND RECOMMENDATIONS}

Local healthcare services cannot make sufficient efforts to uplift the health status of the communities. Community based collaborative interventions are often cost effective, sustainable and effective in managing outbreaks like Hepatitis B and C. According to the given framework, the local healthcare system in Sindh should adopt this model of community engagement to intervene and combat the spread of Hepatitis B and $C$ and prevent its spread. Therefore, it is imperative to engage the local communities and its stakeholders for an informative, collaborative and success oriented approach. Moreover, educating the community stakeholders for on-going basis can be an asset to the public health initiatives in the community. Engaging the community in communicable diseases may be used for engaging into different initiatives related to non-communicable diseases. The government should take further steps to enhance the public health system and framework for the actions against communicable diseases.

\section{REFERENCES}

I. Robinson HM, Hort K. Noncommunicable diseases and health systems reform in low-and-middleincome countries. Pac Health Dialog 2012; I8(I): I 79-90.

2. Ndiaye SM, Quick L, Sanda O, Niandou $S$. The value of community participation in disease surveillance: a case study from Niger. Health Promot Int 2003;18(2):89-98. https://doi.org// 0.1093/heapro//8. 2.89

3. Haldane V, Chuah FL, Srivastava A, Singh SR, Koh GC, Seng CK, et al. Community participation in health services development, implementation, and evaluation: A systematic review of empowerment, health, community, and process outcomes. PLoS One 2019;|4(5):e0216II2. https://doi.org/10.1371/journal.pon e. 0216112

4. Nojilana B, Bradshaw D, Pillay-van Wyk V, Msemburi W, Laubscher R, Somdyala NI, et al. Emerging trends in non-communicable disease mortality in South Africa, 19972010. S Afr Med J 2016;106(5):58. https://doi.org/I0.7I96/SAMJ.2016 .$v 106 \mathrm{i} 5.10674$

5. Adhikari B, Pell C, Phommasone K, Soundala $X$, Kommarasy $P$, Pongvongsa $T$, et al. Elements of effective community engagement: lessons from a targeted malaria elimination study in Lao PDR (Laos). Glob Health Action 2017;10(I): 1366136. https://doi.org/10.1080/ I65497|6.2017.1366136.

6. Morgan MA, Lifshay J. Community engagement in public health. California Endowment under the sponsorship of Contra Costa Health Services (CCHS). 2006: I-8.

7. Aggett $S$. Turning the gaze: challenges of involving biomedical researchers in community engagement with research in Patan, Nepal. Crit Public Health 2018;28(3):30617. https://doi.org//0.1080/ 0958I596.2018.1443203.

8. Abramsky T, Devries K, Kiss L, Nakuti J, Kyegombe N, Starmann E, et al. Findings from the SASA! Study: a cluster randomized controlled trial to assess the impact of a community mobilization intervention to prevent violence against women and reduce HIV risk in Kampala, Uganda. BMC Med 2014;12(I):122. https://doi. org/I0.II86/s I29I6-0I4-0I22-5.

9. Waddington $\mathrm{H}$, Snilstveit B, White $H$, Fewtrell L. Water, sanitation and hygiene interventions to combat childhood diarrhea in developing countries. New Delhi, India: 3ie;
2009 Aug [Accessed on: February 15, 2020] Available from URL: http://www.3ieimpact.org/evidenc e/systematic-reviews/details/23/.

10. Oliver JE, Wood T. Medical conspiracy theories and health behaviors in the United States. JAMA Intern Med 20 I4; I74(5):8I78. https://doi.org//0.100I/ jamainternmed.20I4.190

I I. Demaio AR, Nielsen KK, Tersbøl BP, Kallestrup P, Meyrowitsch DW. Primary Health Care: a strategic framework for the prevention and control of chronic non-communicable disease. Glob Health Action 20I4;7(I):24504. https://doi.org/ 10.3402/gha.v7.24504

12. Theodori GL. Community and community development in resource-based areas: Operational definitions rooted in an interactional perspective. Soc Nat Resour 2005; I8(7):661-9. https://doi.org/ 10.1080/0894|920590959640

13. Mir F, Mahmood F, Siddiqui AR, Baqi S, Abidi SH, Kazi AM, et al. HIV infection predominantly affecting children in Sindh, Pakistan, 2019: a cross-sectional study of an outbreak. The Lancet Infect Dis 2020;20(3): 362-70. https://doi.org/10.1016/ SI473-3099(I9)30743-I

14. Chandio SP, Talpur GH, Rajput MI. Prevalence of Hepatitis-D in Rural Sindh, Pakistan. Univ Sindh J Animal Sci 20।8;2(02):45-7.

I5. Lavery JV, Tinadana PO, Scott TW, Harrington LC, Ramsey JM, YtuarteNuñez C, et al. Towards a framework for community engagement in global health research. Trends Parasitol $2010 ; 26(6): 279-83$. https://doi.org/ 10.1016/j.pt.2010.02.009

16. Sannathimmappa MB, Nambiar V, Arvindakshan R. Hepatitis B: Knowledge and awareness among preclinical year medical students. Avicenna J Med 2019;9(2):43-7. https://doi.org// 0.4 I03/ajm.AJM_I 64_18

17. Whittaker M, Smith C. Reimagining malaria: five reasons to strengthen community engagement in the lead up to malaria elimination. Malar J 
2015; I4(I):410(20I5). https://doi. org/I0.II86/s I 2936-0I5-093I-9

18. Rich KL. Community/Public Health Nursing Ethics. In: Nursing Ethics, Across the Curricullum and Into Practice. Butts JB, Rich KL (eds).
2020, $5^{\text {th }}$ edition. Jones and Bartlett Learning. Burlington, USA.

19. Nyirenda D, Sariola S, Gooding K, Phiri M, Sambakunsi R, Moyo E, et al. 'We are the eyes and ears of researchers and community': Under- standing the role of community advisory groups in representing researchers and communities in Malawi. Dev World Bioeth 2018; 18 (4):420-8. https://doi.org/10.1111// dewb. 12163

\section{AUTHOR'S CONTRIBUTION}

All the authors have made substantial contributions to the manuscript as under:

FI \& MH: Conceiving and designing the review, designed the literature search, screened results of searches, abstracted data from included studies and interpretation of data, drafting the manuscript, critical review, approval of the final version to be published

HS: Conducted the literature search, screened results of searches, drafting the manuscript, approval of the final version to be published

Authors agree to be accountable for all aspects of the work in ensuring that questions related to the accuracy or integrity of any part of the work are appropriately investigated and resolved.

CONFLICT OF INTEREST
Authors declared no conflict of interest
GRANT SUPPORT AND FINANCIAL DISCLOSURE
Authors have declared no specific grant for this research from any
funding agency in the public, commercial or not-for-profit sectors

\section{DATA SHARING STATEMENT}

The data that support the findings of this study are available from the corresponding author upon reasonable request.

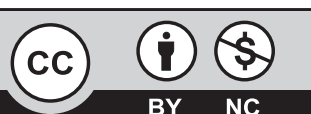

BY NC
This is an Open Access article distributed under the terms of the Creative Commons Attribution-Non Commercial 2.0 Generic License.
KMUJ web address: www.kmuj.kmu.edu.pk

Email address: kmuj@kmu.edu.pk 